\title{
Effects of hydrogen-rich saline on early acute kidney injury in severely burned rats by suppressing oxidative stress induced apoptosis and inflammation
}

\author{
Song-Xue Guo ${ }^{1}$, Quan Fang ${ }^{2}$, Chuan-Gang You' ${ }^{1}$ Yun-Yun Jin' ${ }^{1}$, Xin-Gang Wang ${ }^{1}$, Xin-Lei Hu
} and Chun-Mao Han ${ }^{*}$

\begin{abstract}
Background: Early acute kidney injury (AKI) in severely burned patients predicts a high mortality that is multi-factorial. Hydrogen has been reported to alleviate organ injury via selective quenching of reactive oxygen species. This study investigated the potential protective effects of hydrogen against severe burn-induced early AKI in rats.

Methods: Severe burn were induced via immersing the shaved back of rats into a $100^{\circ} \mathrm{C}$ bath for $15 \mathrm{~s}$. Fifty-six Sprague-Dawley rats were randomly divided into Sham, Burn + saline, and Burn + hydrogen-rich saline (HS) groups, and renal function and the apoptotic index were measured. Kidney histopathology and immunofluorescence staining, quantitative real-time PCR, ELISA and western blotting were performed on the sera or renal tissues of burned rats to explore the underlying effects and mechanisms at varying time points post burn.

Results: Renal function and tubular apoptosis were improved by HS treatment. In addition, the oxidation-reduction potential and malondialdehyde levels were markedly reduced with HS treatment, whereas endogenous antioxidant enzyme activities were significantly increased. HS also decreased the myeloperoxidase levels and influenced the release of inflammatory mediators in the sera and renal tissues of the burned rats. The regulatory effects of HS included the inhibition of p38, JNK, ERK and NF-KB activation, and an increase in Akt phosphorylation.
\end{abstract}

Conclusion: Hydrogen can attenuate severe burn-induced early AKl; the mechanisms of protection include the inhibition of oxidative stress induced apoptosis and inflammation, which may be mediated by regulation of the MAPKs, Akt and NF-kB signalling pathways.

Keywords: Burn insults, Acute kidney injury, Hydrogen, Reactive oxygen species, Inflammation, Apoptosis

\section{Background}

Acute kidney injury (AKI) is a devastating complication that affects patients exposed to severe burn injury [total body surface area (TBSA) $\geq 20 \%]$, which has been associated with a high mortality rate (from 50 to $100 \%$ ) [1, 2]. The pathogenesis of AKI post burn is multifactorial and not completely understood $[1,2]$. Early AKI may be

\footnotetext{
*Correspondence: hanchunmao1@163.com

${ }^{1}$ Department of Burn, Second Affiliated Hospital, School of Medicine, Zhejiang University, 88 Jiefang Road, Hangzhou 310009, Zhejiang, China Full list of author information is available at the end of the article
}

attributed to intravascular hypovolemia, systemic vasoconstriction, early organ dysfunction or myoglobinuria, which appears during the first 5 days post burn and results from systemic inflammatory response syndrome (SIRS) or apoptosis; late AKI may be caused by sepsis, multi-organ failure or drug toxicity [2-5].

Combined with the apoptotic pathway, reactive oxygen species (ROS)-induced oxidative stress is involved in the development of renal dysfunction followed by AKI or other diseases [6, 7]. In addition, inflammation participates in the progression of renal impairment post burn, whereas ROS can induce inflammatory cytokine 
activities via the assistance of the nuclear factor (NF) $-\mathrm{\kappa B}$ pathway [8, 9]. Mitogen-activated protein kinases (MAPKs), including p38 MAPK, c-Jun N-terminal kinase (JNK), and extracellular signal-regulated kinase (ERK), play important roles in the mediation of apoptosis, cellular proliferation and differentiation, and previous studies have verified that MAPKs are involved in the pathogenesis and protection against AKI caused by different stimuli [10]. ROS have been reported to be involved in MAPK activation $[11,12]$.

Ohsawa et al. first reported that molecular hydrogen $\left(\mathrm{H}_{2}\right)$ is a novel, selective antioxidant that specifically neutralises the hydroxyl radical $(\cdot \mathrm{OH})$ and peroxynitrate anion $\left(\mathrm{ONOO}^{-}\right)$, without disturbing metabolic oxidation-reduction or ROS-involved signals [13]. $\mathrm{H}_{2}$ is electrically neutral and much smaller than the oxygen molecule, it can easily penetrate cellular and intracellular membranes, which makes it highly effective in reducing cytotoxic radicals [14]. It also has a protective effect on oxidative stress-induced organ damage $[9,15,16]$. Furthermore, $\mathrm{H}_{2}$ has been shown to suppress inflammation and apoptosis in colitis, hepatitis, graft I/R injury and some chemical-induced organ injuries via the inhibition of inflammatory cell infiltration and the regulation of pro-inflammatory cytokine expression and inflammation/apoptosis-related signalling pathways [17-21]. Both the inhalation of $\mathrm{H}_{2}$ gas and the application of hydrogenrich saline (HS) are effective routes for utilisation of the therapeutic properties of $\mathrm{H}_{2}$, as certified by prior experimental and clinical studies [15, 17, 22-25].

Given that ROS-based oxidative stress, and subsequent apoptosis/inflammatory response all play roles in the pathophysiological development and cytoprotection of burn-induced early AKI and that $\mathrm{H}_{2}$ has anti-oxidative stress, anti-apoptotic and anti-inflammatory effects, we hypothesised that $\mathrm{H}_{2}$ will have a protective effect on renal function after severe burn. In addition, details regarding the regulation of intrinsic signalling pathways were included in this study. Based on previous experiments, in this study, we selected $\mathrm{HS}$ as a $\mathrm{H}_{2}$ carrier and intraperitoneal (IP) administration as an effective and convenient application method [23].

\section{Methods}

\section{Animals and treatment}

All experiments protocols on animals in this study were approved by the Committee on Animal Care of Second affiliated hospital, School of Medicine, Zhejiang University (No. 2015-140) and strictly abided by the National Institutes of Health Guidelines for the Care and Use of Laboratory Animals. Adult male Sprague-Dawley (SD) rats (weighing approximately 220-250 g) were purchased from the Animal Centre of Zhejiang Chinese Medical
University (Hangzhou, China) and were housed on a 12-h light/dark cycle in an air-filtered unit with consistent temperature and humidity and free access to food and water. The animals were randomly assigned to seven groups (Figure 1), including the Sham group (saline, $10 \mathrm{ml} / \mathrm{kg}$, immediate IP injection post water immersion) and three Burn + vehicle (saline, $10 \mathrm{ml} / \mathrm{kg}$, immediate IP injection post burn) and three Burn + hydrogen saline (HS, $10 \mathrm{ml} / \mathrm{kg}$, immediate IP injection post burn) groups ( $\mathrm{n}=8$ per group). The rats in the Burn + vehicle groups and Burn + HS groups were sacrificed by overdoses of sodium pentobarbital at 6,24 or $72 \mathrm{~h}$ post burn, while those in the Sham group were sacrificed at $72 \mathrm{~h}$ post water exposure. Both kidneys were dissected after cardiac perfusion with phosphate-buffered saline (PBS) $(\mathrm{pH}=7.2)$ and were maintained in $10 \%$ formalin at $4^{\circ} \mathrm{C}$ or in a $-80^{\circ} \mathrm{C}$ freezer for subsequent experiments.

\section{Severe burn model}

After a SD rat was anaesthetised with sodium pentobarbital (50 mg/ $\mathrm{kg}$, IP injection), the shaved back of the rat was immersed into $100^{\circ} \mathrm{C}$ hot water for $15 \mathrm{~s}$, generating a full-thickness dermal burn model with $40 \%$ TBSA [26]. The Sham group was exposed to $25^{\circ} \mathrm{C}$ water after anaesthesia [26]. Liquid resuscitation with lactated Ringer solution (LRS) at $4 \mathrm{ml} / \mathrm{kg} / \mathrm{TBSA}$ was performed via IP injection immediately and $6 \mathrm{~h}$ after the operation. All rats were housed in individual cages and given $0.25 \mathrm{mg} / \mathrm{kg}$ buprenorphine by subcutaneous injection immediately and every $12 \mathrm{~h}$ post burn for analgesia. The pain and distress scale, reported previously, were conducted immediately and every $6 \mathrm{~h}$ after recovering from anaesthesia to evaluate the pain condition of rat models and instruct pain-reliving therapy [27].

\section{HS preparation}

Hydrogen-rich saline was prepared as previously described [16, 23, 28]. In general, $\mathrm{H}_{2}$ was dissolved in $0.9 \%$ saline for $6 \mathrm{~h}$ under $0.4 \mathrm{MPa}$ pressure to a supersaturated condition using HS-producing apparatuses from the Department of Diving Medicine, the Second Military Medical University, Shanghai, China. Gas chromatography (Biogas Analyzer Systems-1000, Mitleben, Japan) was applied to monitor the hydrogen concentration (maintained at greater than $0.6 \mathrm{mmol} / \mathrm{l}$ in HS [13]).

\section{Drug administration}

The rats in the three-time-point post burn $(6,24,72 \mathrm{~h})$ Burn + HS groups received HS $(10 \mathrm{ml} / \mathrm{kg})$ by IP injection immediately after SAH induction, which was re-administered every $12 \mathrm{~h}$ before sacrifice. An equal volume of $0.9 \%$ saline $(10 \mathrm{ml} / \mathrm{kg})$ was IP-injected into the SAH models of the three Burn + vehicle groups $(6,24,72 \mathrm{~h})$ immediately 


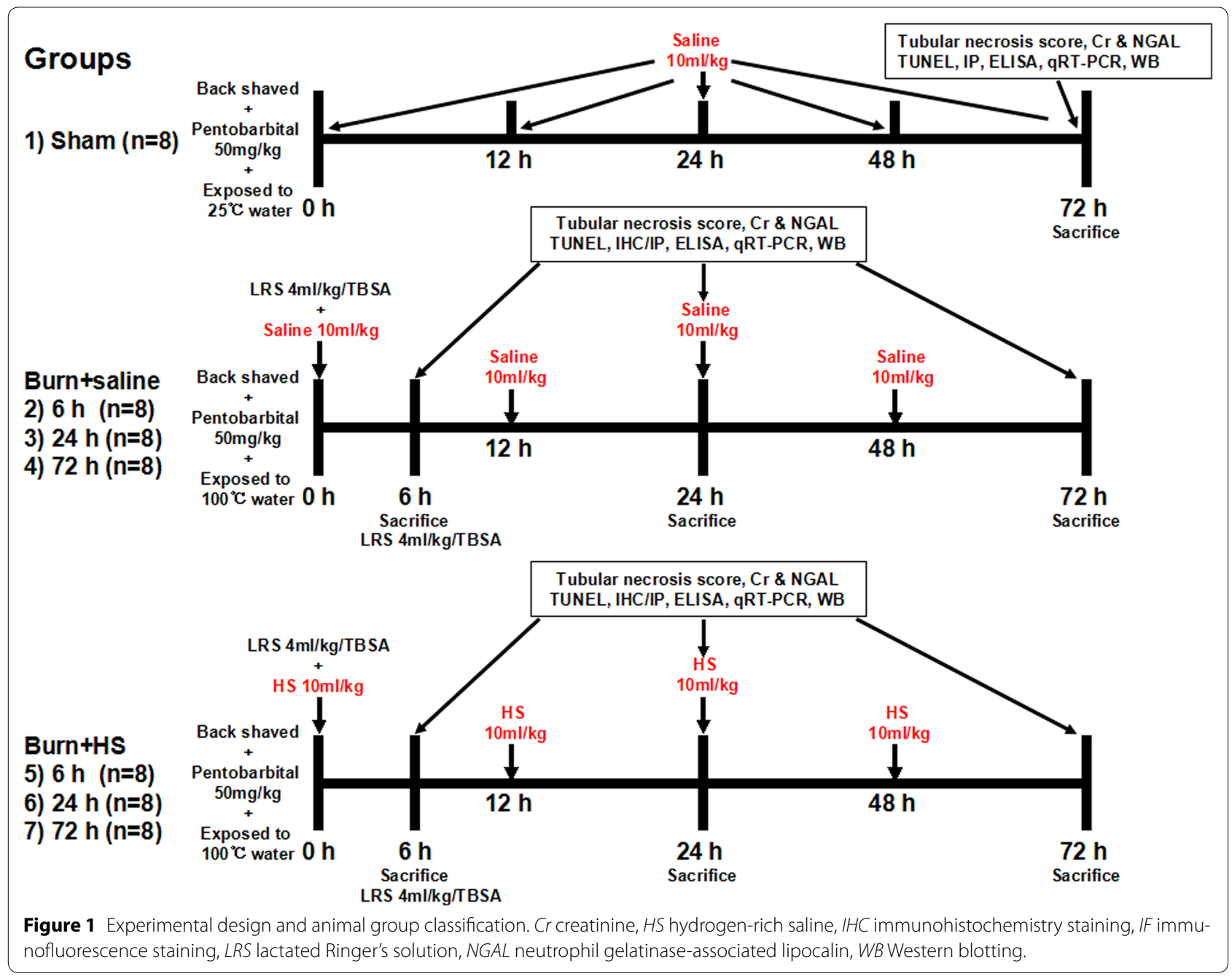

and every $12 \mathrm{~h}$ after $\mathrm{SAH}$ induction. The Sham group was given $0.9 \%$ saline immediately and every $12 \mathrm{~h}$ post warmwater exposure.

\section{Histological evaluation}

The fixed kidneys were cut into 7- $\mu \mathrm{m}$-thick sections for haematoxylin and eosin (HE) staining, and the tissue slices were observed under the microscope. Histological changes were scored based on the percentage of renal cortical tubules that expressed epithelial necrosis, and these changes were ranked as 0 : normal, 1 : less than $10 \%$, 2: $11-25 \%, 3: 26-75 \%$, and 4: greater than $75 \%$. Ten highmagnification files for every slice were randomly selected for blinded observation.

\section{Renal function evaluation}

Rat blood samples were collected to measure the serum levels of creatinine $(\mathrm{Cr})$ via a clinical chemistry analyser system and kits (Prochem-V, Drew Scientific, Dallas, TX, USA). The serum neutrophil gelatinase-associated lipocalin (NGAL) levels were detected in the various groups using a Rat NGAL ELISA kit (Boster, Wuhan, China) according to the manufacturer's instructions.

\section{Measurement of redox potential, lipid peroxidation} and antioxidant enzymatic activity

The oxidation-reduction potential (redox potential, ORP) value was determined using the HI3131B electrode (Hanna Co, Ltd, Italy) according to the provided instructions. For detection, 0.5\% renal tissue homogenate was injected into the device under airtight conditions at $25.2^{\circ} \mathrm{C}$. The renal tissue homogenate reacted with a thiobarbituric acid reactive species (TBARS) assay kit (KeyGEN, Nanjing, China), and this reaction was used to obtain the malondialdehyde (MDA) levels. Tissue superoxide dismutase (SOD), glutathione peroxidase 
(GSH-Px) and catalase (CAT) activities were measured using commercial assay kits from KeyGEN Biotech (Nanjing, China) according to the manufacturer's protocols. The absorbance values were measured using a microplate reader (Model 680 Microplate Reader, BIO-RAD, CA, USA).

\section{TUNEL staining for apoptosis}

The commercial cell death detection kit was purchased from Roche Diagnostics (Indianapolis, IN, USA). The stained slices were observed and photographed under a microscope (DM5500B, Leica, Solms, Germany), and the apoptotic index was determined as the percentage of apoptotic cells versus the total number of cells counted in a blinded manner.

\section{Immunohistochemistry (IHC) staining}

Paraffin-embedded tissues (5- $\mu$ m-thick slices) were examined by IHC and IF staining. Some sections were incubated with anti-myeloperoxidase (MPO) antibodies (Abcam, Cambridge, UK) overnight at $4^{\circ} \mathrm{C}$. Then, they were incubated with goat anti-rabbit secondary antibody (Boster, Wuhan, China), and visualised with a 3,3-diaminobenzidine (DAB) kit (Boster, Wuhan, China). Finally, the mounted sections were observed and photographed under a microscope at $200 \times$ magnification (DM2500, Leica, Solms, Germany).

\section{Detection of renal tissue MPO activity}

Tissue homogenate were obtained for the detection of MPO activity using a rat-specific ELISA kit according to the manufacturer's instructions (Lianshuo, Shanghai, China).

\section{Quantitative real-time PCR (qRT-PCR) analysis of renal} tissue

The expression levels of TNF- $\alpha$, IL-1 $\beta$, IL-6, IL-10 and ICAM-1 were analysed via qRT-PCR. Briefly, total RNA was isolated from tissues with TRIzol Reagent (Invitrogen, Carlsbad, CA, USA) and RNase-Free DNase I (Qiagen, Duesseldorf, Germany). The SuperScript FirstStrand Synthesis System for reverse transcription PCR (RT-PCR) (Invitrogen, Carlsbad, CA, USA) was applied to synthesise cDNAs, and RNA and cDNA concentrations and purities were measured via BIO-RAD spectrophotometry (SmartSpecTM Plus, BIO-RAD, CA, USA). The primers (Table 1) were designed using Primer Premier 6.0 software and were synthesised by Shanghai Biological Engineering Co., Ltd. (Shanghai, China). PCR amplifications were conducted using the Power SYBR ${ }^{\circ}$ Master Mix (Invitrogen, Carlsbad, CA, USA) in an $\mathrm{iQ}^{\mathrm{m}} 5$ Real-time PCR system (BIO-RAD, CA, USA). Expression levels were assessed relative to that of $18 \mathrm{~S}$ rRNA, as an internal standard, and the details are shown in Table 1. Relative quantification of the target gene expression levels was conducted using the $2^{-\Delta \Delta \mathrm{Ct}}$ method.

\section{Western blotting analysis}

The protein samples of the right kidneys were mixed with loading buffer and subjected to SDS-PAGE. The transferred membranes were subsequently blocked and incubated overnight at $4^{\circ} \mathrm{C}$ with the following primary antibodies: anti-cleaved caspase-3, anti-Akt, anti-p-Akt, anti-p38, anti-p-p38, anti-ERK, anti-p-JNK, anti-JNK (all from Santa Cruz, CA, USA), anti-NF-kB p65 (both from Abcam, Cambridge, UK), and anti-p-ERK (Cell Signalling Technology, Boston, USA). $\beta$-actin (Santa Cruz, CA, USA) was blotted on the same membranes and served as the control. The protein bands were detected with SuperSignal $^{\circ}$ West Dura Extended Duration Substrate (Pierce, USA) and X-ray Film (Kodak, USA) and were then analysed with Bandscan 5.0 software and compared with $\beta$-actin.

\section{Statistical analysis}

The data are presented as the mean \pm standard error of the means (SEMs). GraphPad Prism version 5.01 (San

Table 1 The oligonucleotide primers used for PCR amplification

\begin{tabular}{|c|c|c|c|c|}
\hline Gene & Genbank accession & Primer sequences $\left(5^{\prime}-3^{\prime}\right)$ & Size (bp) & Annealing $\left({ }^{\circ} \mathrm{C}\right)$ \\
\hline Rat TNF- $\alpha$ & NM_012675.3 & $\begin{array}{l}\text { GCCACCACGCTCTTCTGTCTACTG } \\
\text { TGGGCTACGGGCTTGTCACTC }\end{array}$ & 152 & 64 \\
\hline Rat IL-1 $\beta$ & NM_031512.2 & $\begin{array}{l}\text { GCTTTCGACAGTGAGGAGAATGAC } \\
\text { CTGCTGTGAGATTTGAAGCTGGAT }\end{array}$ & 126 & 64 \\
\hline Rat IL-6 & NM_012589.2 & $\begin{array}{l}\text { TGACAGCCACTGCCTTCCCTAC } \\
\text { CAATCAGAATTGCCATTGCACAA }\end{array}$ & 169 & 64 \\
\hline Rat IL-10 & NM_012854.2 & $\begin{array}{l}\text { GCACTGCTATGTTGCCTGCTCTT } \\
\text { GAGCATGTGGGTCTGGCTGACT }\end{array}$ & 111 & 64 \\
\hline Rat ICAM-1 & NM_012967.1 & $\begin{array}{l}\text { CACAAACGACGCTTCTTTTTGCTCT } \\
\text { CCCCTCTTGCCAGGTCCAGTT }\end{array}$ & 144 & 64 \\
\hline Rat 185 (reference substance) & M11188 & GAATTCCCAGTAAGTGCGGGTCATA & 105 & 64 \\
\hline
\end{tabular}


Diego, CA, USA) and SPSS 19 (SPSS, Chicago, IL, USA) were used for the statistical analyses. The comparisons between the Sham group and each of the burn groups, which were treated with saline or HS, were conducted using Mann-Whitney U tests. Multiple comparisons among groups treated with saline or HS at different times were analysed with two-way analysis of variance (ANOVA) followed by Bonferroni's post hoc tests. A value of $\mathrm{p}<0.05$ was accepted as statistically significant.

\section{Results}

HS attenuates the severity of renal tubular damage and the elevation of serum Cr and NGAL levels in severely burned rats

HE-stained slices were analysed via histological examination (Figure 2a). The tubular damage scores significantly increased in the rats at $6 \mathrm{~h}$ post burn and remained elevated at $72 \mathrm{~h}$ post burn, although a slight decrease was observed at $24 \mathrm{~h}$ (all $\mathrm{p}<0.05$, vs Sham) (Figure $2 \mathrm{~b}$ ). Similarly, significant elevations in serum $\mathrm{Cr}$ levels were observed post burn at three time points (all $\mathrm{p}<0.05$, vs Sham) (Figure 2c). For HS treatment, the tubular damage scores in the rats were significantly decreased at the different time points post burn injury (all $\mathrm{p}<0.05$, vs corresponding Burn + saline) (Figure $2 b$ ); in addition, the $\mathrm{Cr}$ levels were reduced (Figure 2c). After severe burn insult, the serum NGAL levels in the rats were markedly elevated at $6 \mathrm{~h}$ and were improved at $24 \mathrm{~h}$ but remained significantly higher than those of the Sham group (all $\mathrm{p}<0.05$ ) (Figure 2d). The NGAL levels clearly increased again at $72 \mathrm{~h}$ post burn $(\mathrm{p}<0.05)$ (Figure $2 \mathrm{~d})$. HS treatment caused a remarkable decline in the NGAL levels in the sera of burned rats at various time points after burn (all p < 0.05), and we observed the lowest NGAL level of the three Burn + HS groups in the 24-h group (Figure 2d).

\section{HS relieves severe burn-induced oxidative stress in the renal tissues of rats}

After burn injury, all three time point groups displayed significant elevations in their ORP values in renal tissues

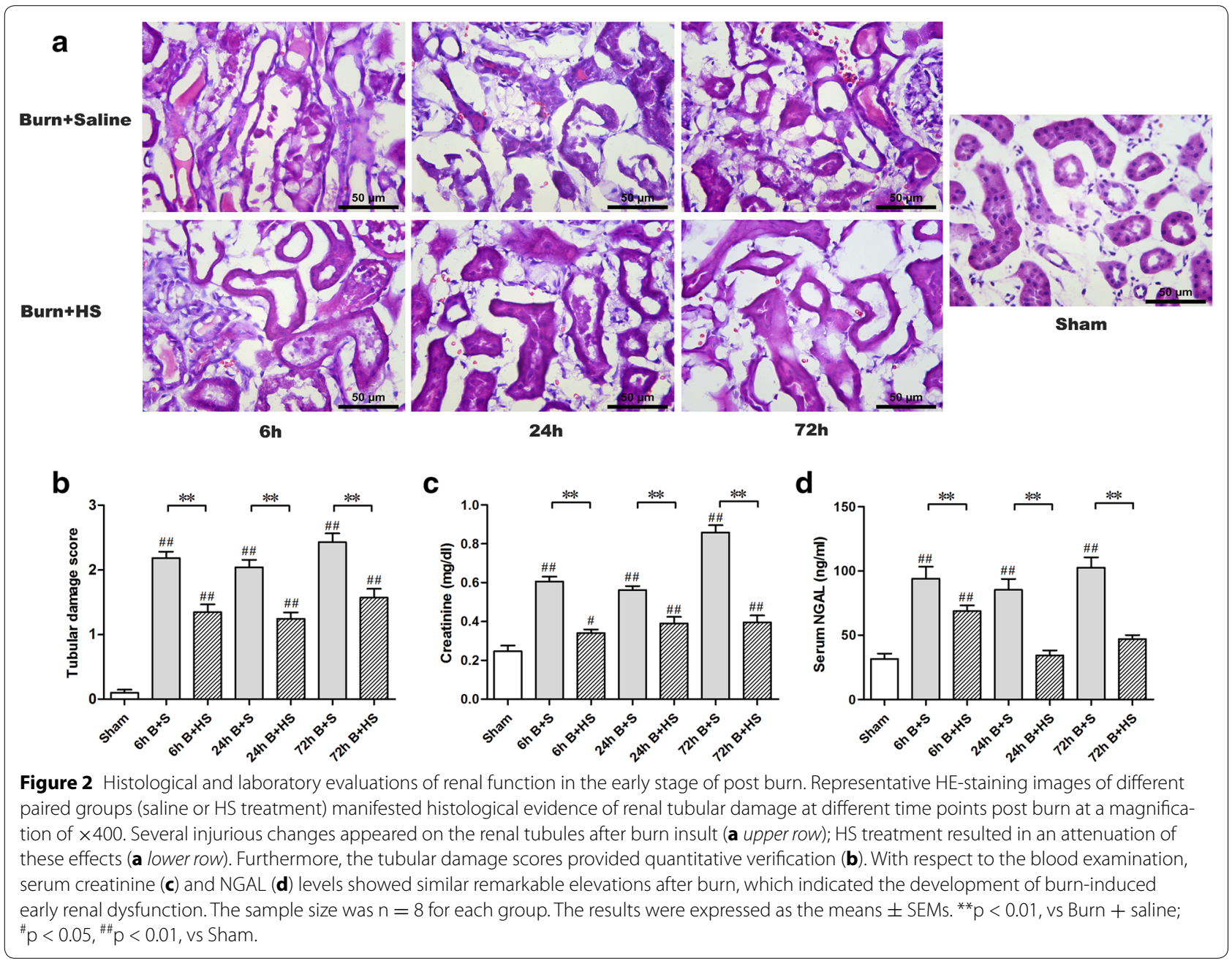


compared with the Sham group (all $\mathrm{p}<0.05$, vs Sham) (Figure 3a). HS treatment gave rise to marked reductions in the ORP value in the corresponding groups (all $\mathrm{p}<0.05$, vs corresponding Burn + saline) (Figure 3a). Additionally, severe burn induced a sharp increase in the MDA level at $6 \mathrm{~h}$ ( $\mathrm{p}<0.05$, vs Sham) (Figure 3b). Subsequently, the extent of MDA elevation gradually decreased at 24 and $72 \mathrm{~h}$, despite the levels of both groups being obviously higher than that of the Sham group (both $\mathrm{p}<0.05$, vs Sham) (Figure 3b). HS treatment significantly decreased the increases in MDA levels at all three time points (all $\mathrm{p}<0.05$, vs corresponding Burn + saline) (Figure $3 \mathrm{~b}$ ). Extensive burn injury also reduced the activities of endogenous antioxidant enzymes (total SOD, GSH-Px, CAT) (all p $<0.05$, vs Sham) (Figure 3c-e), and HS application significantly reversed the reduction of antioxidant enzyme activities post burn (all $\mathrm{p}<0.05$, vs corresponding Burn + saline) (Figure 3c-e).

\section{Apoptosis evaluation}

As shown in Figure 4a, b, the number of tubular apoptotic cells rose significantly at $6 \mathrm{~h}$ post burn, gradually increased afterwards, and then continually increased to $72 \mathrm{~h}$ (all p $<0.05$, vs Sham), whereas HS treatment substantially ameliorated burn-induced renal tissue apoptosis in the 6-, 24- and 72-h Burn + HS groups (all $\mathrm{p}<0.05$ ). In addition, burn injury caused a consistent elevation in cleaved caspase-3 (activated caspase-3, indicating apoptosis) levels from 6 to $72 \mathrm{~h}$ post burn, all of which were dramatic (all $\mathrm{p}<0.05$, vs Sham), while HS injection clearly attenuated this trend (all $\mathrm{p}<0.05$, vs corresponding Burn + saline) (Figure 4c). In terms of pro-apoptotic protein expression, the protein level of cleaved caspase-3 increased remarkably with time post burn, whilst caspase-3 showed a similar expression trend from 6 to $72 \mathrm{~h}$ after burn insult (all p $<0.05$, vs Sham) (Figure $4 \mathrm{~d}$, e). After HS administration, the expressions of cleaved caspase- 3 and caspase- 3 at the three times exhibited drastic declines, in contrast to the corresponding Burn + saline groups (all p < 0.05) (Figure 4d, e). The ratio of cleaved caspase-3/caspase- 3 represents the actual activation of caspase- 3 and reflects apoptosis induction. Although the ratio of cleaved caspase-3/caspase-3 remained unchanged at $6 \mathrm{~h}$ post burn when compared with the Sham group, a slight increase was observed at $24 \mathrm{~h}$, and a marked increase was observed at $72 \mathrm{~h}$. The ratio of cleaved caspase-3/caspase- 3 for the three HS treatment groups $(6,24$ and $72 \mathrm{~h}$ ) levelled out at a lower level, and a significant difference compared to the Burn + saline group occurred at $72 \mathrm{~h}$ post burn.

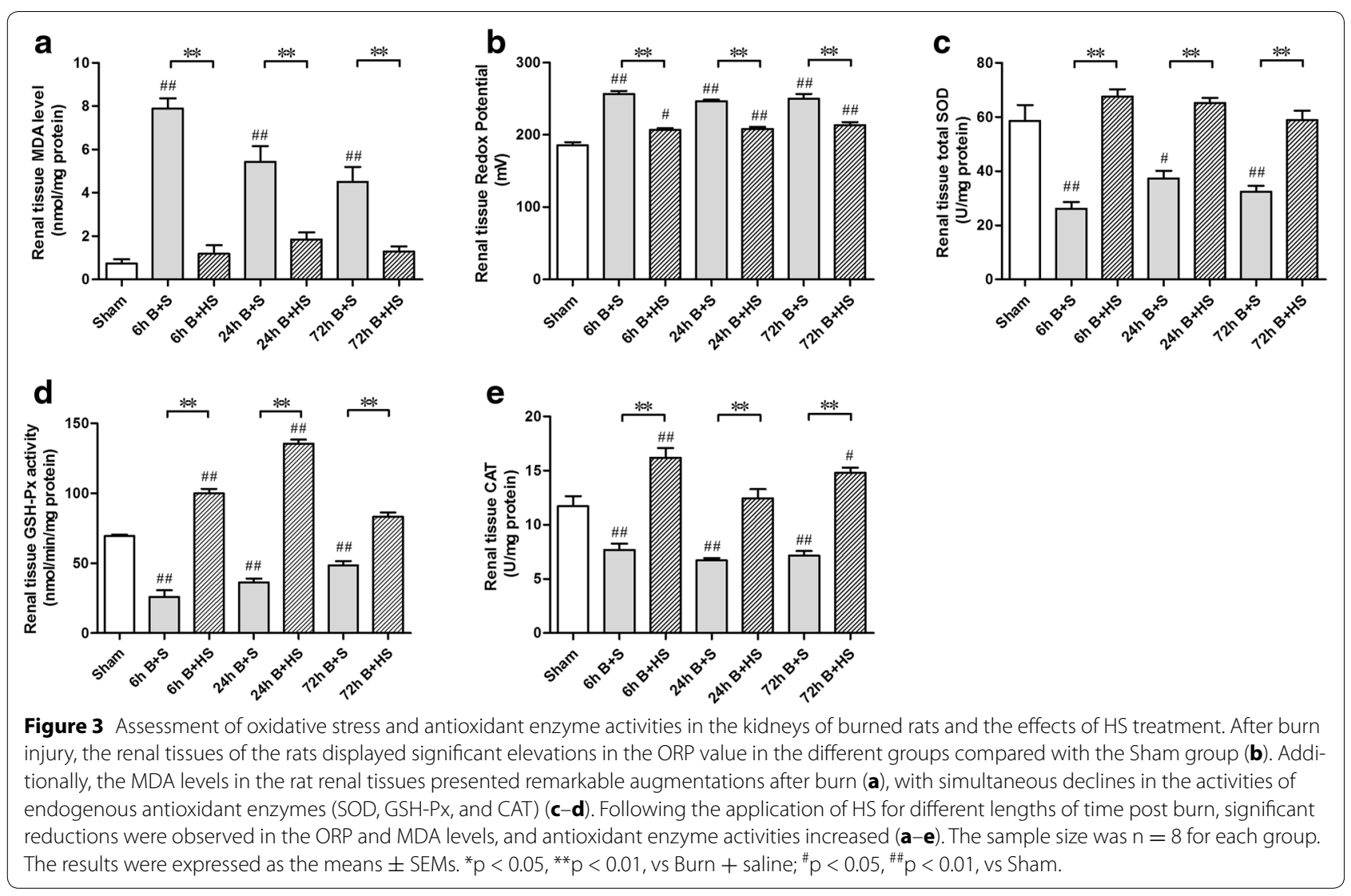




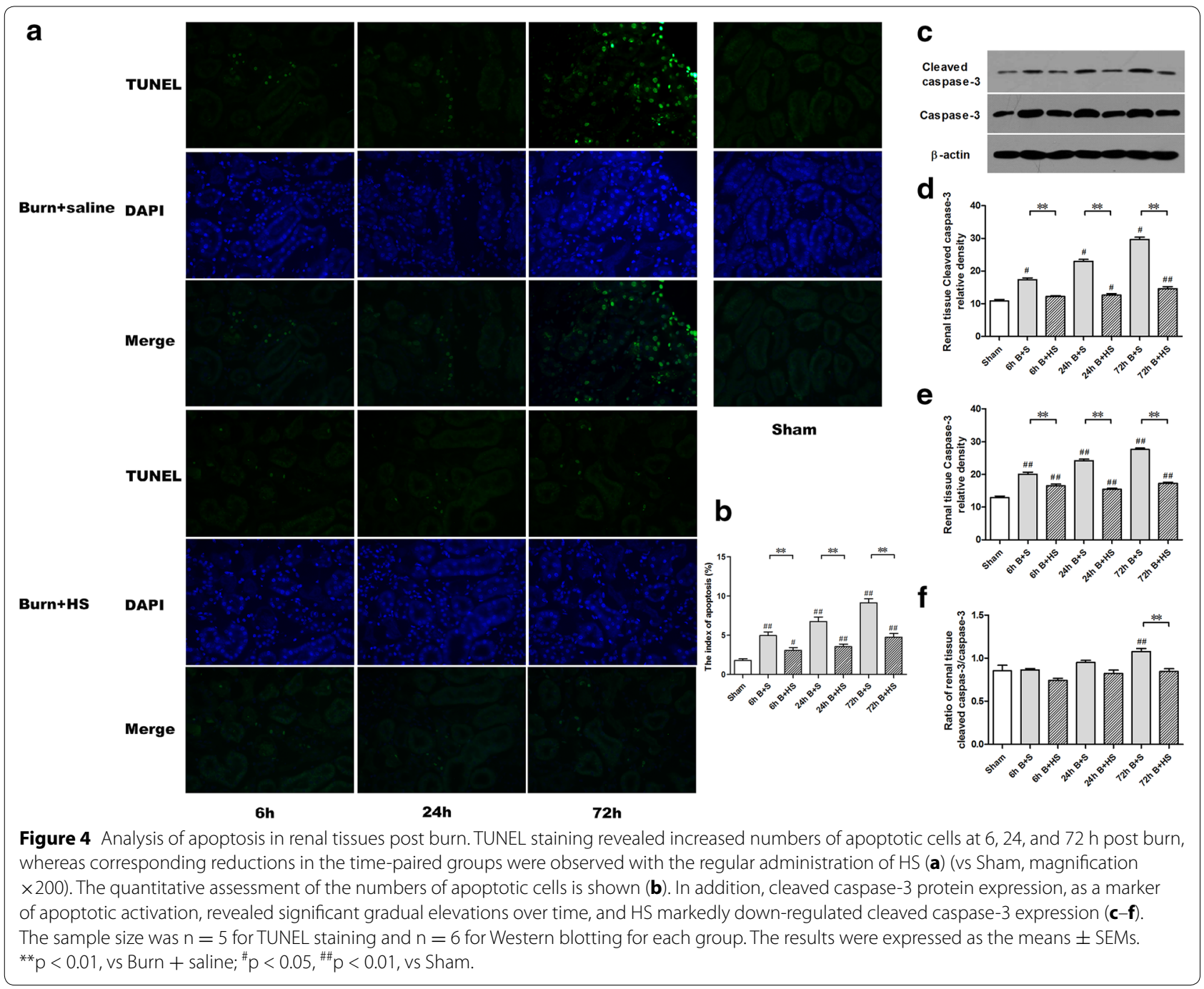

\section{Changes in MPO and inflammatory mediators in kidneys post burn and after HS treatment}

MPO was detected via IHC staining in rat kidneys after burn injury (Figure 5a). HS treatment was associated with decreased numbers of positively labelled cells in renal tissues (Figure 5a). Severe burn injury also led to gradually elevated renal tissue MPO levels from 6 to $72 \mathrm{~h}$ (all p $<0.05$, vs Sham) (Figure 5b), whereas these burninduced MPO level increases were significantly lowered in the three Burn + HS groups at 24 and $72 \mathrm{~h}$ (all $\mathrm{p}<0.05$ ) (Figure $5 \mathrm{~b}$ ).

Moreover, the mRNA expression of TNF- $\alpha$ and IL- $1 \beta$ in renal tissues was markedly increased at $6 \mathrm{~h}$ post burn ( $<<0.05$, vs Sham), and the extent of this increase was reduced at $24 \mathrm{~h}$ post burn injury but was elevated again at $72 \mathrm{~h}$ post burn ( $<0.05$, vs Sham) (Figure 6a, b). In addition, the elevated mRNA expression of
IL-6 gradually decreased over time in the rat kidneys, although all mRNA expression levels at the three time points were significantly elevated (all $\mathrm{p}<0.05$, vs Sham) (Figure 6c). The levels of both IL-10 and ICAM-1 were clearly increased at $6 \mathrm{~h}$ and continued to increase until $72 \mathrm{~h}$ post burn (all p $<0.05$, vs Sham) (Figure 6d, e). After HS treatment, the mRNA expression levels of the selected inflammatory mediators were markedly reduced in all time-paired Burn + HS groups (all $\mathrm{p}<0.05$ ) (Figure $6 \mathrm{a}-\mathrm{c}, \mathrm{e}$ ), whereas the increase of IL-10 expression became more remarkable (all $\mathrm{p}<0.05$, vs corresponding Burn + saline) (Figure 6d).

\section{Western blotting assessment of signalling proteins}

Following severe burn injury, phosphorylated Akt (p-Akt) levels were significantly increased at $6 \mathrm{~h}$ and peaked at $24 \mathrm{~h}$ post burn, followed by a reduction in this elevation 


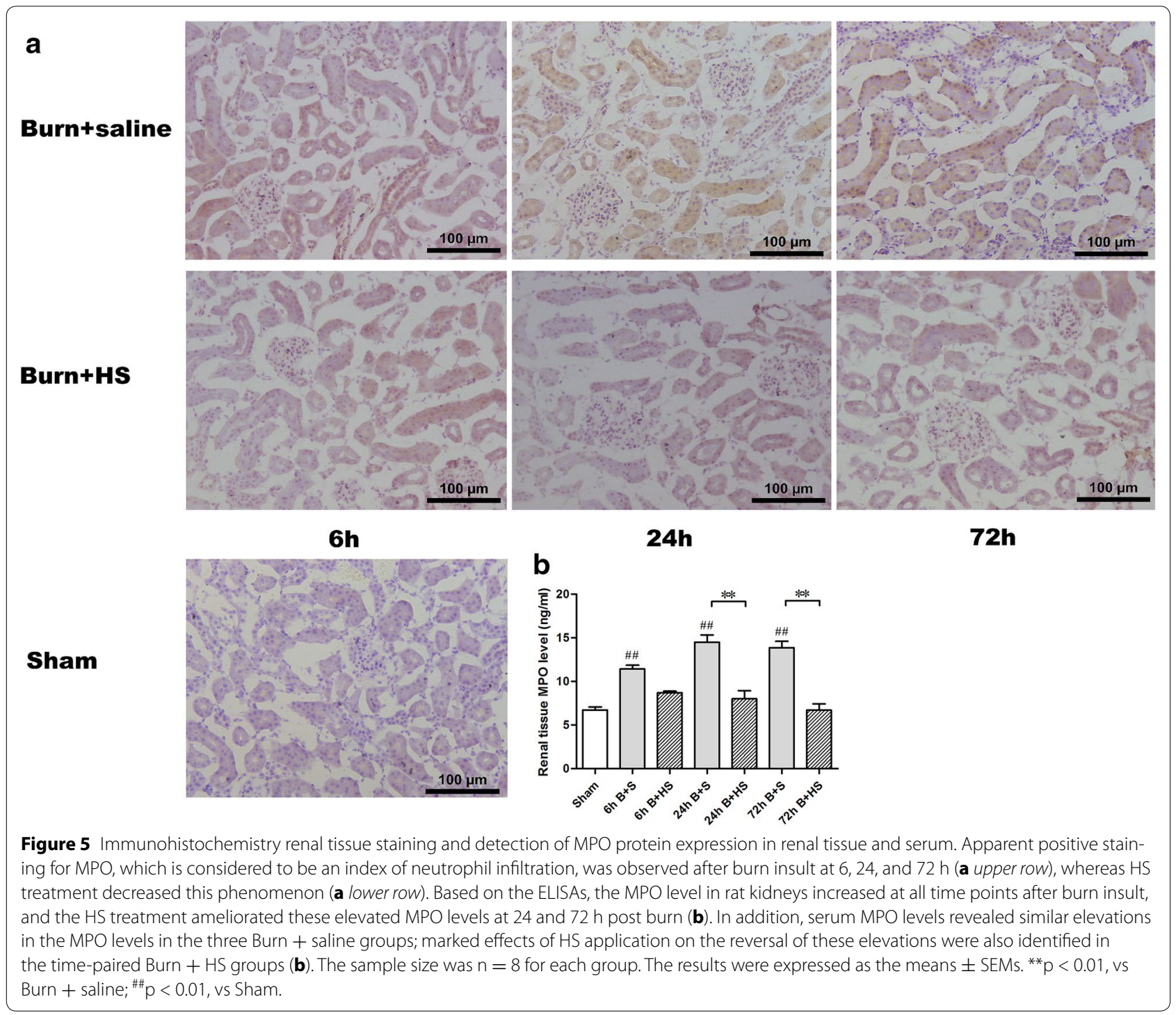

at $72 \mathrm{~h}$ (all p $<0.05$, vs Sham) (Figure 7a). The levels of activated p38, i.e., phosphorylated p38 (p-p38), exhibited a marked, stepwise elevation from 6 to $72 \mathrm{~h}$ (all $\mathrm{p}<0.05$, vs Sham) (Figure 7b). Following HS treatment, HS clearly promoted the further augmentation of the p-Akt/Akt ratio (all $\mathrm{p}<0.05$, vs corresponding Burn + saline) (Figure $7 \mathrm{a})$. In contrast, the ratio of $\mathrm{p}-\mathrm{p} 38 / \mathrm{p} 38$ in the renal tissues of severely burned rats markedly decreased in all time groups (all $\mathrm{p}<0.05$, vs corresponding Burn + saline) and ultimately reached a similar value as that of the Sham group at $72 \mathrm{~h}$ (Figure $7 \mathrm{~b}$ ).

Although obvious changes in p-ERK protein expression were observed post burn (all $\mathrm{p}<0.05$, vs Sham) (Figure 7c), HS treatment led to significant down-regulation of $\mathrm{p}$-ERK at all selected time points (all p $<0.05$, vs corresponding Burn + saline) (Figure $7 \mathrm{c}$ ). Furthermore, the activated pro-apoptotic kinase JNK (p-JNK) exhibited increased expression after burn injury, and the most significant elevation was observed at $72 \mathrm{~h}$ post burn (all $\mathrm{p}<0.05$, vs Sham) (Figure 7d); the elevation of p-JNK levels was markedly down-regulated by HS administration (all $\mathrm{p}<0.05$, vs corresponding Burn + saline) (Figure 7d).

As a subunit of the NF- $\mathrm{kB}$ dimer, p65 has typically been chosen as an index of NF- $\kappa B$ activation [29]. Although NF- $\kappa B$ p 65 protein expression was significantly increased at 6,24 and $72 \mathrm{~h}$ post burn (all $\mathrm{p}<0.05$, vs Sham), the trend towards increased expression decreased with time (Figure 7e). HS displayed an apparent effect of decreasing the increased protein expression of NF- $\kappa B$ p 65 at all thee time points (all $\mathrm{p}<0.05$, vs corresponding Burn + saline), with the greatest reduction observed at $72 \mathrm{~h}$ post burn (Figure 7e). 

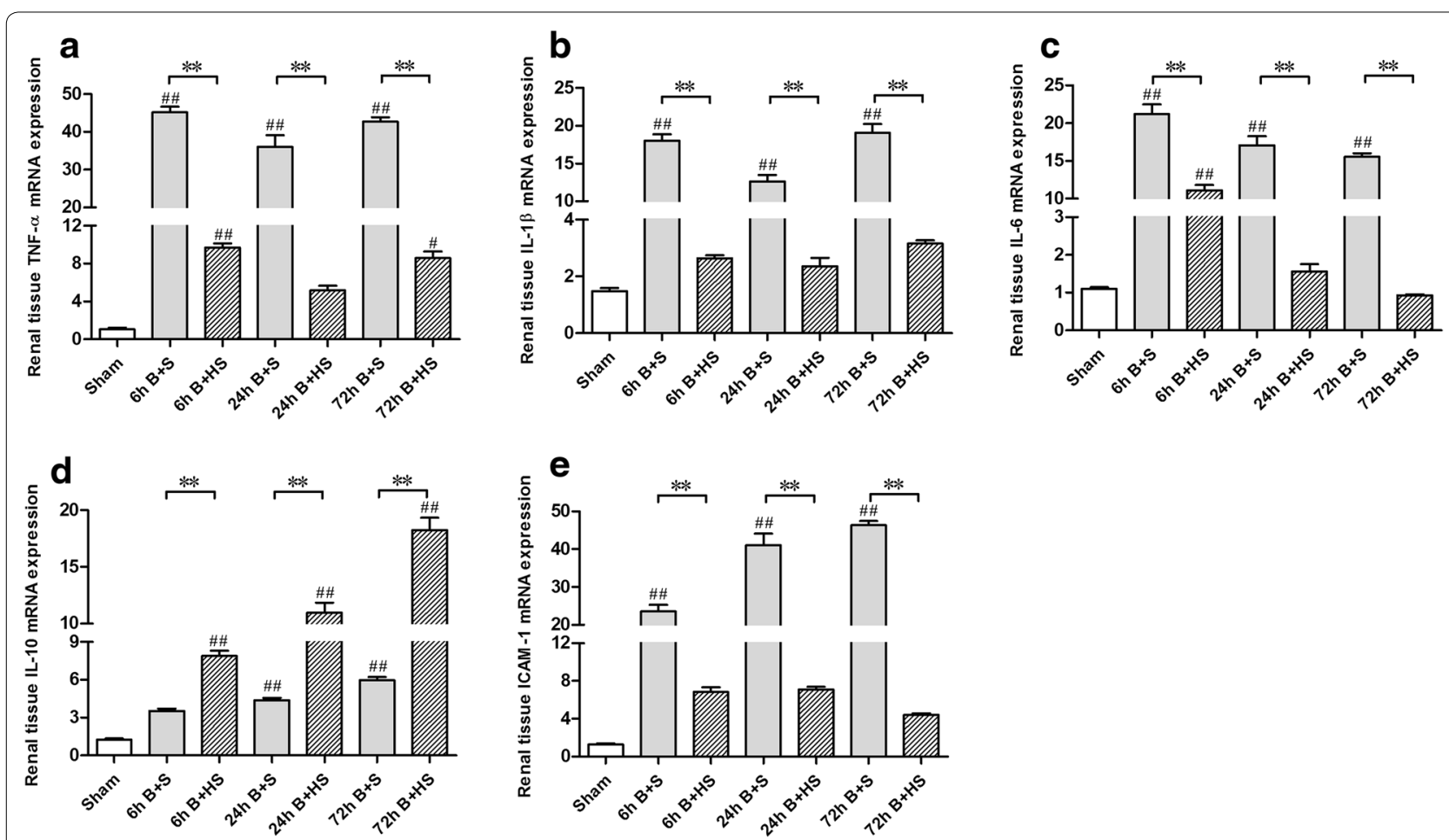

Figure 6 Quantitative RT-PCR analysis of inflammatory mediators in the renal tissues of severely burned rats. The qRT-PCR analysis revealed that HS treatment could significantly attenuate the clear elevation in mRNA expression after burn in the rat kidneys $(\mathbf{a}-\mathbf{c}, \mathbf{e})$. Additionally, positive IHC results for IL-10 were observed post burn, and more positive renal cells were identified with HS treatment at various time points (d). Although the expression of IL-10 mRNA markedly increased with time, HS treatment appeared to enhance this increase in the kidneys of burned rats (d). The sample size was $n=6$ for each group. The results are expressed as the means \pm SEMs. ${ }^{*} p<0.05$, ${ }^{* *} p<0.01$, vs Burn + saline; ${ }^{\#} p<0.05$, ${ }^{\# \#} p<0.01$, vs Sham.

\section{Discussion}

In the present study, we first explored the potential protective effect of HS on AKI after severe burn in rats. The experimental results demonstrated that HS represents a potentially novel therapeutic medium for AKI post severe burn injury that provides protection via anti-oxidative stress, anti-apoptotic and anti-inflammatory effects. Moreover, HS might further regulate the MAPKs/Akt/ NF- $\kappa B$ signalling pathways (Figure 8 ).

Acute kidney injury is typically associated with injurious histological changes to renal tissue cells, including the absence of the proximal tubular brush border, blebbing of apical membranes, separation of tubular epithelial cells from the basement membrane, or aggregation of cells and proteins in the luminal region [30]. We also observed tubular epithelial necrosis by microscopic detection, similar to other studies on AKI caused by different reasons [31-33]. Applied HS, less necrotic tubules were found with a lower tubular damage score, which suggests a relief of early AKI post burn. In addition, the serum $\mathrm{Cr}$ and NAGL levels reflect renal function alteration and represent sensitive indicators or biomarkers of AKI [5, 30, 34-36]. Serum creatinine level elevation, including an increase of at least $0.3 \mathrm{mg} / \mathrm{dl}$ or $50 \%$, combined with a reduction in urine output (documented oliguria of less than $0.5 \mathrm{ml} / \mathrm{kg}$ per hour for more than $6 \mathrm{~h}$ ), is also one of the current standard criteria for AKI diagnosis [37]. After the critical burn insult, the rat kidneys presented progressive histologic injuries with time, in parallel renal dysfunction was also observed according to the serum $\mathrm{Cr}$ and NAGL results. The regular management of HS via the IP route effectively ameliorated renal tissue damage and improved burn-induced renal dysfunction, all of which suggested the protective potential of HS on early AKI post burn.

Substantial evidence has suggested that ROS and oxidative stress play vital roles in the pathogenesis of AKI, and similar effects have been verified in other burn-induced tissue injuries [38-42]. Because of the abundance of polyunsaturated fatty acids, the kidney is considered vulnerable to ROS-mediated oxidative stress, with the ability to generate ROS itself $[43,44]$. Moreover, the aberrant and excessive production of free radicals such as $\cdot \mathrm{OH}$ and $\mathrm{ONOO}^{-}$results in vascular constriction and immoderate consumption of endogenous anti-oxidant enzymes such as SOD, GSH-Px, and CAT, eventually giving rise 


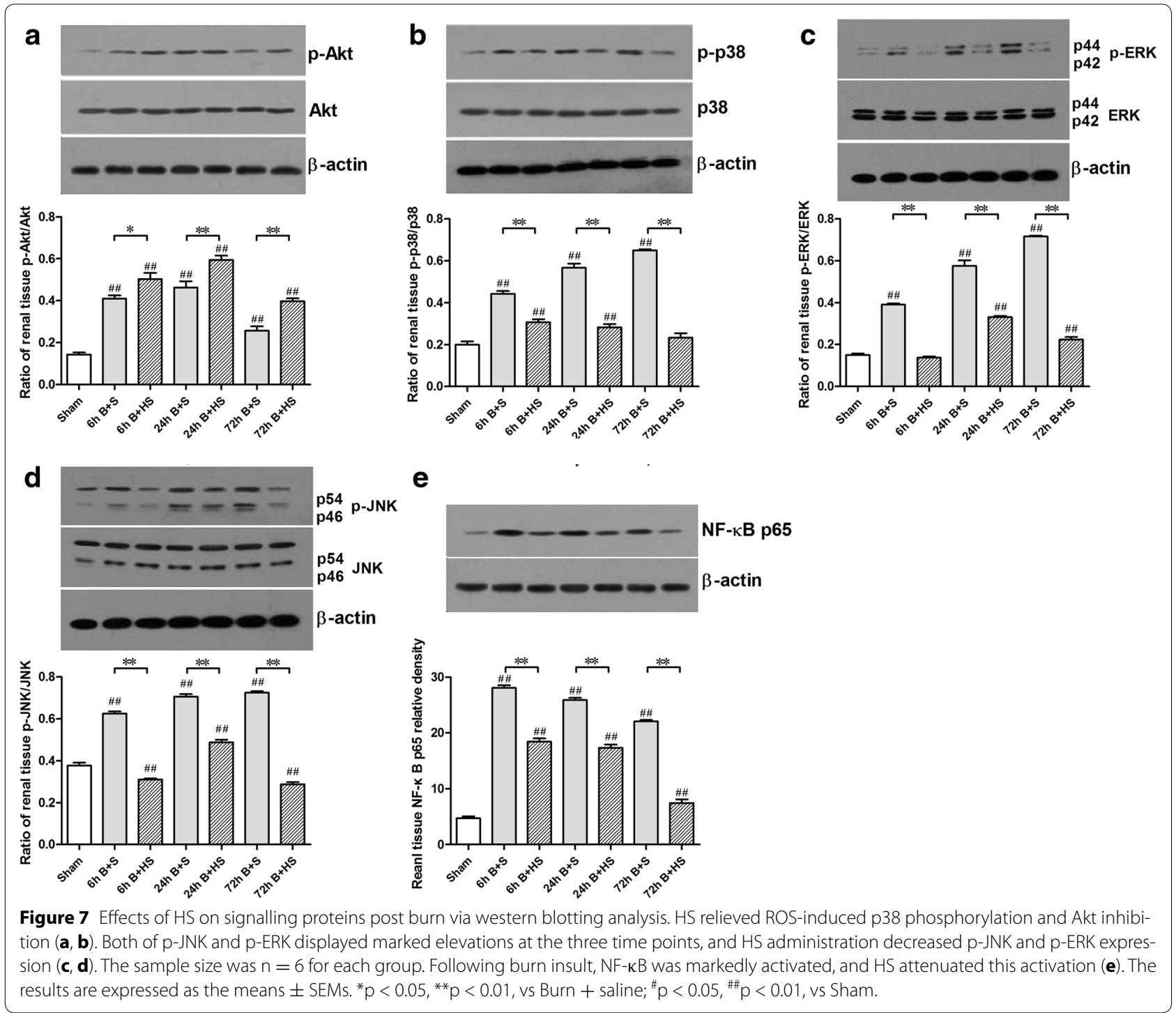

to organ injury $[13,23,45]$. In our study, HS exhibited a strong ability to attenuate severe burn-induced oxidative stress damage to renal tissues by scavenging free radicals and up-regulating endogenous anti-oxidant enzyme activities.

Apoptosis is a common response of the kidney when confronting insults such as a burn, ischaemia, radiation, trauma, or toxic injury [46-49]. Mariano et al. demonstrated that pro-apoptotic mediators in the circulatory system contribute to renal functional alterations after burn injury [47]. Furthermore, ROS-related oxidative stress induces mitochondrial dysfunction and tubular epithelial cell apoptosis after burn injury via triggering a series of apoptotic mediators [30,50]. We observed the obvious induction of apoptosis in renal tissue post burn, and persistent ROS-related oxidative stress played roles in the progression of apoptosis. Similar to prior reports, our results of increased cleaved caspase- 3 expression and number of TUNEL-positive cells, which corresponded to the prior renal function evaluation results, indicated that the most severe AKI conditions occurred at $72 \mathrm{~h}$, following increased renal failure. In this study, HS treatment significantly reduced renal cell apoptosis in the rat burn model, and this was verified to be an anti-apoptotic effect.

The inflammatory response also participates in the onset and development of early AKI post burn [51, 52]. Generally, cell necrosis can cause the loss of cell membrane integrity and the uncontrolled release of products of cell death into the extracellular space, all of which can initiate an inflammatory response in the surrounding tissue and finally result in advanced tissue injury [53]. 


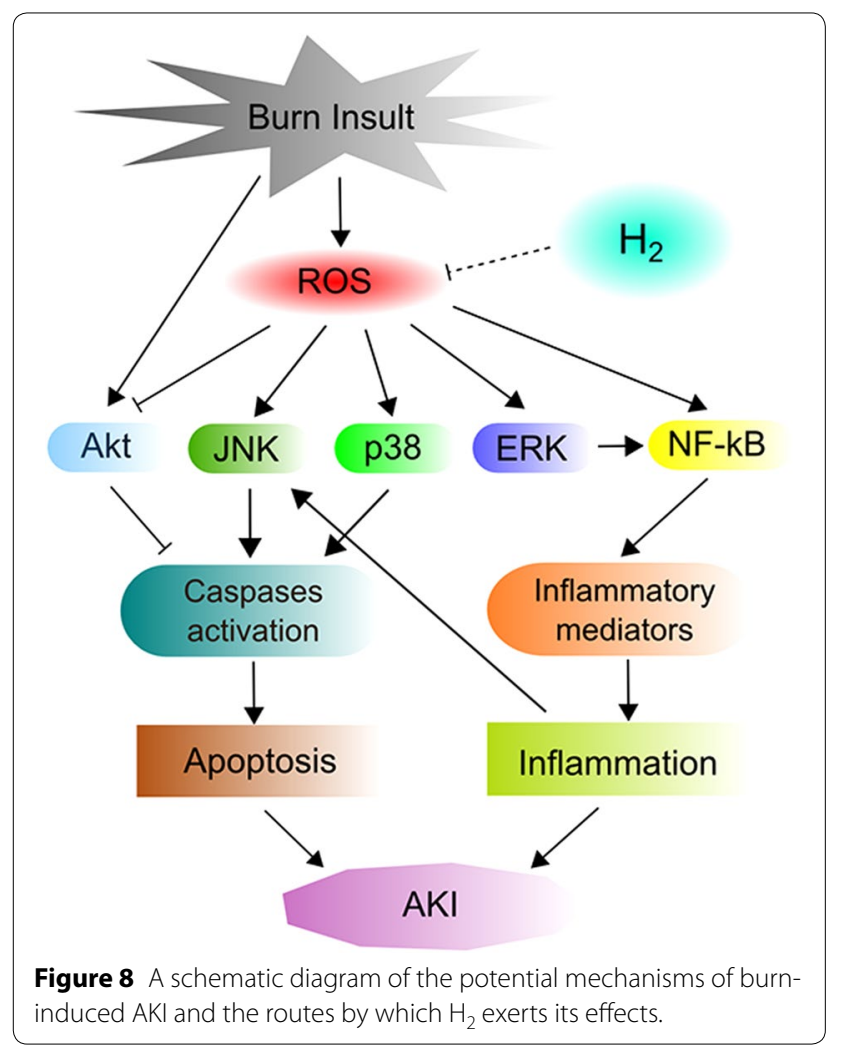

Therefore, as well as systemic response caused by local burn wound, the tubular necrosis also contributes to the inflammatory injury in kidneys of burned rats [54, 55]. The extent of inflammation can indirectly reflect the level of tissue necrosis. In addition, the release of circulatory and tissue inflammatory mediators might cause increased vascular permeability and tubular damage, which could eventually lead to filtration failure and tubular dysfunction. In terms of inflammatory mediators, ROS-related oxidative stress may initiate inflammatory cascades that result in pathophysiological organ changes [56]. Inflammatory cytokines and adhesion molecules such as TNF$\alpha$, IL-1 $\beta$, IL-6, and ICAM-1 trigger a strong inflammatory response to injurious stimuli [4], whereas MPO signifies an inflammatory condition by reflecting the infiltration of neutrophils [40]. IL-10 is an anti-inflammatory cytokine that is generated by monocytes/macrophages and $\mathrm{T}$ and B lymphocytes, which antagonise the inflammatory response and regulate auto-immunity [57]. We observed and examined renal tissue MPO levels using IHC staining and ELISA and discovered that the MPO levels of rat renal tissues were markedly augmented post burn, indicating the potentially important role of inflammatory cell infiltration in tissue injury post burn. The study conducted by previous researchers demonstrated that $\mathrm{H}_{2}$ could effectively attenuate LPS/burn-induced lung neutrophil recruitment and inflammation supported by the down-regulation of tissue MPO and proinflammatory cytokines (TNF- $\alpha$, IL-1 $\beta$, IL-6) [20, 40]. In addition, Cardinal et al. suggested that administration of hydrogen water (similar to HS) significantly attenuated the intragraft production of inflammatory cytokines (TNF- $\alpha$, IL-6, ICAM-1 and INF- $\gamma$ ) after kidney allotransplantation [21]. In several in vivo and in vitro studies, $\mathrm{H}_{2}$ was reported to bring about a further increase in IL-10 levels after endotoxin stimulation as a way to attenuate inflammation $[58,59]$. In our study, the final results showed that $\mathrm{H}_{2}$ ameliorates AKI after severe burn in rats through an anti-inflammatory effect that involves the down-regulation of inflammation-related enzymes and cytokines and up-regulation of anti-inflammatory cytokines in the circulation and local tissues.

Afterwards, we estimated the potential value of MAPKs and Akt signalling in the beneficial effects of $\mathrm{H}_{2}$ on early AKI post burn. As a family of serine/threonine protein kinases, MAPKs are considered to be responsible for most cellular responses to cytokines and external stress signals and are vital for the induction of apoptosis and inflammatory mediators [60, 61]. In terms of p38 MAPK, its activation has been reported to participate in the induction of apoptosis and inflammatory response in local wounds and remote organs after burn insults [54, 62-66]. In addition, previous studies also indicated that p38 MAPK plays an important role in the development of renal injuries via its regulation on renal cell apoptosis and the release of local or systemic inflammatory mediators [67-69]. Feng et al. demonstrated that phosphorylated p38 MAPK, regarding as an activated condition, plays a more important role in the induction of renal cell apoptosis, which contributes to the renal injury post burn [30]. In the present study, we observed a similar activation of p38 MAPK in the renal tissue after burn, paralleling with the enhanced tubular apoptosis and the release of pro-inflammatory cytokines, which suggests p38 MAPK may be involved in the progress of early AKI post burn through regulating burn-induced apoptosis and inflammation. In common knowledge, JNK has been implicated in mitochondrial death and its activation contributes to cell apoptosis [11, 70]. Several previous studies reported that JNK activation in renal samples was associated with tubular cell apoptosis after renal ischemia-reperfusion [13]. Recently, Marshall et al. demonstrated the silence of JNK2 could alleviate the hepatic apoptosis post burn [71]. In addition, it was reported that the JNK pathway plays a critical role in the smoke-induced lung injury and the application of JNK inhibitor could attenuate the airway apoptosis [72]. Except ROS, JNK can also be activated by some 
pro-inflammatory cytokines including TNF and IL-1 [73]. Due to a significant increase of JNK phosphorylation and corresponding tubular apoptosis in rats' kidney post burn, we speculated it may play an important role in regulating burn-induced tubular apoptosis. ERK, another important member of MAPKs, has been suggested that its activation is associating with cell survival in several kinds of renal injuries. However, in this study, the burn-induced activation of ERK in rats' kidney did not company with the corresponding decrease of tubular apoptosis. Therefore, ERK may be involved in the other aspect of the mechanism of burn-induced AKI rather than inhibiting tubular apoptosis. In an in vivo study, Seo and collaborators demonstrated that activated ERK induces the dissociation of I $B \alpha$ from $\mathrm{NF}-\kappa \mathrm{B}$, therefore allowing nuclear translocation and DNA-binding of NF- $\mathrm{KB}$ and the subsequent production of pro-inflammatory cytokines [74]. The result of our study exerted that the phosphorylation of ERK, as activated ERK, was paralleled with the increase of NF- $\kappa$ B p 65 expression and the release of pro-inflammatory mediators, which suggests ERK participates in the regulation of tissue inflammation during the process of burn-induced early AKI. In view that ROS can trigger activation of signaling pathways involved in cell migration and invasion such as MAPKs, $\mathrm{H}_{2}$ is like to influence some members of ROS to achieve its effect [75]. Although $\mathrm{H}_{2}$ has been observed to influence some signal transduction pathways, some researchers believe that this is based on its role as an indirect modulator rather than as a molecule binding directly to signalling receptors. In contrast, Itoh and colleagues regarded $\mathrm{H}_{2}$ as a gaseous signalling molecule due to the result showing that $\mathrm{H}_{2}$ could attenuate the phosphorylation of Fc\&RI-associated Lyn as well as its downstream signal transduction (such as JNK, p38 MAPK, ERK) in rat RBL-2H3 mast cells, followed by the inhibition of NADPH oxidase activity and reduction of hydrogen peroxide $\left(\mathrm{H}_{2} \mathrm{O}_{2}\right)$ levels [76]. In addition to ROS activation, JNK can be activated by the LPS-induced inflammatory response and attenuated by hydrogen inhalation [77]. The data, obtained from human histocytic lymphoma U937 cells, indicated that $\mathrm{H}_{2} \mathrm{O}_{2}$ and .OH could activate PI3K-Akt and PLC-Ras-Raf-ERK signaling pathways [78], whereas $\mathrm{Xu}$ and Zhang discovered that saturated HS decreased LPS-induced ERK phosphorylation in a rat model of acute liver dysfunction [79]. Moreover, Sobue et al. indicated that $\mathrm{H}_{2}$ can attenuate ERK, p38 MAPK, and NF- $\kappa B$ activation in mouse livers [80]. Taken together, we suggested $\mathrm{H}_{2}$ may inhibit NF- $\mathrm{KB}$ activation by reducing oxidative radicals-induced ERK phosphorylation, which allows degradation of $\mathrm{I} \kappa \mathrm{B} \alpha$ from NF- $\kappa \mathrm{B}$. Correspondingly, Akt is an important downstream signal of the classic PI3KAkt pathway, and Akt activation has been regarded as a cell survival factor that antagonises apoptosis in renal tissue exposed to heavy metal or burn insult [30, 61]. The protective effects of Akt in apoptosis include enhancing the capacities of antioxidant and anti-apoptotic proteins and reducing the capacities of pro-apoptotic proteins [61]. Moreover, the significant activation of Akt in rat kidneys was observed in the early stage after burn insults, while a late decrease in Akt activation appeared with increased ROS [30, 81]. Considering the other possible routes resulting in the activation of Akt and our results, the effect of $\mathrm{H}_{2}$ on Akt phosphorylation may be attributed to its effect on ROS-mediated Akt inhibition. Taken together, we determined that the regular administration of HS could down-regulate the $\mathrm{p}-\mathrm{p} 38 / \mathrm{p} 38, \mathrm{p}-\mathrm{JNK} / \mathrm{JNK}$, and $\mathrm{p}$-ERK/ERK ratios, as well as up-regulate Akt phosphorylation.

In a series of previous experiments, NF- $\kappa B$ signalling was implicated in AKI induced by various stimuli, such as I/R injury, haemorrhagic shock, lipopolysaccharide (LPS), or cisplatin, via interactions with TNF- $\alpha$, IL-1 $\beta$, ICAM- 1 , etc. [82-88]. In addition, ROS has been reported to participate in NF- $\mathrm{KB}$ pathway activation, which is unsurprising given the oxidant-sensitive properties of NF- $\kappa B$ [86]. The protective effect of $\mathrm{H}_{2}$ has been manifested in several models of inflammatory injury based on its inhibition of inflammatory cell infiltration, NF- $\kappa \mathrm{B}$ activation and proinflammatory cytokine production [23]. Furthermore, $\mathrm{H}_{2}$ has been reported to inhibit cytokine-induced LOX-1 gene expression by directly suppressing IкB $\alpha$ to downregulate NF- $\kappa B$ activation [89]. On the other hand, the increase in infection-caused free radicals contributed to the subsequent degradation of cytosolic $\operatorname{I\kappa B} \alpha$ and to the nuclear translocation of NF- $\mathrm{kB}$ subunits (p65 and p50), and $\mathrm{H}_{2}$ indirectly inhibited NF- $\mathrm{KB}$ signalling through reducing oxygen-free radicals [13]. ERK may be also involved in regulation of $\mathrm{H}_{2}$ on NF- $\kappa \mathrm{B}$ signalling, considering its reported regulation on NF- $\kappa B$ activation [74]. Our results indicate that HS may protect the kidneys of burned rats from AKI via negatively regulating NF- $\mathrm{KB}$ signalling.

\section{Conclusion}

In summary, the present study first demonstrates the protective effects of $\mathrm{H}_{2}$ against early AKI following severe burn in rats. The beneficial effects of this treatment are a result of its ability to relieve oxidative stress, apoptosis and inflammation and may be mediated by the complex modulation of the MAPKs, Akt and NF- $\mathrm{kB}$ signalling pathways. 


\section{Authors' contributions}

SXG carried out the molecular studies, participated in the sequence alignment, immunoassays, ELISA assay, experiment design and drafted the manuscript. QF carried out the immunoassays and participated in the design of the study. CGY and YYJ participated in the sequence alignment and model production. XGW and XLH participated in the design of the study and performed the statistical analysis. CMH conceived of the study, and participated in its design and coordination and helped to draft the manuscript. All authors read and approved the final manuscript.

\section{Author details}

${ }^{1}$ Department of Burn, Second Affiliated Hospital, School of Medicine, Zhejiang University, 88 Jiefang Road, Hangzhou 310009, Zhejiang, China. ${ }^{2}$ Department of Plastic Surgery, Binjiang Branch, Second Affiliated Hospital, School of Medicine, Zhejiang University, 1511 Jianghong Road, Hangzhou 310000, Zhejiang, China. ${ }^{3}$ Department of Orthopedic, Binjiang Branch, Second Affiliated Hospital, School of Medicine, Zhejiang University, 1511 Jianghong Road, Hangzhou 31000, Zhejiang, China.

\section{Acknowledgements}

Professor Xue-Jun Sun, from the Department of Diving Medicine, the Second Military Medical University, provided special assistance on the preparation of hydrogen-rich saline, and experimental design. This work was supported by National Natural Science Foundation of China (NSFC) Grant 81401591, and Zhejiang Provincial National Natural Science Foundation of China Grant Q13H150002.

\section{Compliance with ethical guidelines}

\section{Competing interests}

The authors declare that they have no competing interests.

Received: 6 March 2015 Accepted: 26 May 2015

Published online: 06 June 2015

\section{References}

1. Palmieri T, Lavrentieva A, Greenhalgh DG (2010) Acute kidney injury in critically ill burn patients. Risk factors, progression and impact on mortality. Burns 36:205-211

2. Steinvall I, Bak Z, Sjoberg F (2008) Acute kidney injury is common, parallels organ dysfunction or failure, and carries appreciable mortality in patients with major burns: a prospective exploratory cohort study. Crit Care 12:R124

3. Mustonen KM, Vuola J (2008) Acute renal failure in intensive care burn patients (ARF in burn patients). J Burn Care Res 29:227-237

4. Sun IF, Lee SS, Lin SD, Lai CS (2007) Continuous arteriovenous hemodialysis and continuous venovenous hemofiltration in burn patients with acute renal failure. Kaohsiung J Med Sci 23:344-351

5. Yavuz S, Anarat A, Acarturk S, Dalay AC, Kesiktas E, Yavuz M et al (2014) Neutrophil gelatinase associated lipocalin as an indicator of acute kidney injury and inflammation in burned children. Burns 40:648-654

6. Sahu BD, Rentam KK, Putcha UK, Kuncha M, Vegi GM, Sistla R (2011) Carnosic acid attenuates renal injury in an experimental model of rat cisplatin-induced nephrotoxicity. Food Chem Toxicol 49:3090-3097

7. Wagener FA, Dekker D, Berden JH, Scharstuhl A, van der Vlag J (2009) The role of reactive oxygen species in apoptosis of the diabetic kidney. Apoptosis 14:1451-1458

8. Li H, Huang K, Liu X, Liu J, Lu X, Tao K et al (2014) Lithium chloride suppresses colorectal cancer cell survival and proliferation through ROS/GSK-3 beta/NF-kappa B signaling pathway. Oxid Med Cell Longev 2014:241864

9. Zhao L, Wang YB, Qin SR, Ma XM, Sun XJ, Wang ML et al (2013) Protective effect of hydrogen-rich saline on ischemia/reperfusion injury in rat skin flap. J Zhejiang Univ Sci B 14:382-391

10. Feliers D, Kasinath BS (2011) Erk in kidney diseases. J Signal Transduct 2011:768512

11. Kunduzova OR, Bianchi P, Pizzinat N, Escourrou G, Seguelas MH, Parini A et al (2002) Regulation of JNK/ERK activation, cell apoptosis, and tissue regeneration by monoamine oxidases after renal ischemia-reperfusion. FASEB J 16:1129-1131
12. Schroeter H, Boyd C, Spencer JP, Williams RJ, Cadenas E, Rice-Evans C (2002) MAPK signaling in neurodegeneration: influences of flavonoids and of nitric oxide. Neurobiol Aging 23:861-880

13. Ohsawa I, Ishikawa M, Takahashi K, Watanabe M, Nishimaki K, Yamagata Ket al (2007) Hydrogen acts as a therapeutic antioxidant by selectively reducing cytotoxic oxygen radicals. Nat Med 13:688-694

14. Kurioka T, Matsunobu T, Satoh Y, Niwa K, Shiotani A (2014) Inhaled hydrogen gas therapy for prevention of noise-induced hearing loss through reducing reactive oxygen species. Neurosci Res 89:69-74

15. Hayashida K, Sano M, Ohsawa I, Shinmura K, Tamaki K, Kimura K et al (2008) Inhalation of hydrogen gas reduces infarct size in the rat model of myocardial ischemia-reperfusion injury. Biochem Biophys Res Commun 373:30-35

16. Zhuang Z, Zhou ML, You WC, Zhu L, Ma CY, Sun XJ et al (2012) Hydrogenrich saline alleviates early brain injury via reducing oxidative stress and brain edema following experimental subarachnoid hemorrhage in rabbits. BMC Neurosci 13:47

17. Buchholz BM, Kaczorowski DJ, Sugimoto R, Yang R, Wang Y, Billiar TR et a (2008) Hydrogen inhalation ameliorates oxidative stress in transplantation induced intestinal graft injury. Am J Transpl 8:2015-2024

18. Kajiya M, Sato K, Silva MJ, Ouhara K, Do PM, Shanmugam KT et al (2009) Hydrogen from intestinal bacteria is protective for concanavalin A-induced hepatitis. Biochem Biophys Res Commun 386:316-321

19. Kajiya M, Silva MJ, Sato K, Ouhara K, Kawai T (2009) Hydrogen mediates suppression of colon inflammation induced by dextran sodium sulfate. Biochem Biophys Res Commun 386:11-15

20. Xie K, Yu Y, Huang Y, Zheng L, Li J, Chen H et al (2012) Molecular hydrogen ameliorates lipopolysaccharide-induced acute lung injury in mice through reducing inflammation and apoptosis. Shock 37:548-555

21. Cardinal JS, Zhan J, Wang Y, Sugimoto R, Tsung A, McCurry KR et al (2010) Oral hydrogen water prevents chronic allograft nephropathy in rats. Kidney Int 77:101-109

22. Fukuda Kl, Asoh S, Ishikawa M, Yamamoto Y, Ohsawa I, Ohta S (2007) Inhalation of hydrogen gas suppresses hepatic injury caused by ischemia/ reperfusion through reducing oxidative stress. Biochem Biophys Res Commun 361:670-674

23. Hong Y, Guo S, Chen S, Sun C, Zhang J, Sun X (2012) Beneficial effect of hydrogen-rich saline on cerebral vasospasm after experimental subarachnoid hemorrhage in rats. J Neurosci Res 90:1670-1680

24. Guo SX, Jin YY, Fang Q, You CG, Wang XG, Hu XL et al (2015) Beneficial effects of hydrogen-rich saline on early burn-wound progression in rats. PLoS One 10:e0124897

25. Wang X, Yu P, Yong Yang, Liu X, Jiang J, Liu D et al (2015) Hydrogen-rich saline resuscitation alleviates inflammation induced by severe burn with delayed resuscitation. Burns 41:379-385

26. Gao C, Huan J, Li W, Tang J (2009) Protective effects of ulinastatin on pancreatic and renal damage in rats following early scald injury. Burns 35:547-552

27. Abali AE, Cabioglu T, Ozdemir H, Haberal M (2015) Interactive effects of acupuncture on pain and distress in major burns: an experiment with rats. Burns 41:833-842

28. Xie K, Yu Y, Chen H, Han H, Sun X, Wang G (2013) Therapeutic effects of hydrogen-rich saline on peritonitis-induced septic shock in rats. $\mathrm{Br}$ J Anaesth 110:148-149

29. Guo C, Liang F, Shah Masood W, Yan X (2014) Hydrogen sulfide protected gastric epithelial cell from ischemia/reperfusion injury by Keap1 s-sulfhydration, MAPK dependent anti-apoptosis and NF-kappaB dependent anti-inflammation pathway. Eur J Pharmacol 725:70-78

30. Feng Y, Liu Y, Wang L, Cai X, Wang D, Wu K et al (2013) Sustained oxidative stress causes late acute renal failure via duplex regulation on p38 MAPK and Akt phosphorylation in severely burned rats. PLoS One 8:e54593

31. Homma K, Yoshida T, Yamashita M, Hayashida K, Hayashi M, Hori S (2015) Inhalation of hydrogen gas is beneficial for preventing contrastinduced acute kidney injury in rats. Nephron Exp Nephrol 128:116-122. doi:10.1159/000369068

32. Merter AA, Mayir B, Erdogan O, ColakT (2015) Protective effects of amifostine on ischemia-reperfusion injury of rat kidneys. Indian J Pharmacol 47:185-189

33. Yan R, Li Y, Zhang L, Xia N, Liu Q, Sun H et al (2015) Augmenter of liver regeneration attenuates inflammation of renal ischemia/reperfusion injury through the NF-kappa B pathway in rats. Int Urol Nephrol 47:861-868 
34. Hong DY, Lee JH, Park SO, Baek KJ, Lee KR (2013) Plasma neutrophil gelatinase-associated lipocalin as early biomarker for acute kidney injury in burn patients. J Burn Care Res 34:e326-e332

35. Si YN, Bao HG, Xu L, Wang XL, Shen Y, Wang JS et al (2014) Dexmedetomidine protects against ischemia/reperfusion injury in rat kidney. Eur Rev Med Pharmacol Sci 18:1843-1851

36. Tasanarong A, Kongkham S, Itharat A (2014) Antioxidant effect of Phyllanthus emblica extract prevents contrast-induced acute kidney injury. BMC Complement Altern Med 14:138

37. Chung KK, Stewart IJ, Gisler C, Simmons JW, Aden JK, Tilley MA et al (2012) The acute kidney injury network (AKIN) criteria applied in burns. J Burn Care Res 33:483-490

38. Arora S, Kaur T, Kaur A, Singh AP (2014) Glycine aggravates ischemia reperfusion-induced acute kidney injury through $\mathrm{N}$-methyl-D-aspartate receptor activation in rats. Mol Cell Biochem 393:123-131

39. Billings FT, Yu C, Byrne JG, Petracek MR, Pretorius M (2014) Heme oxygenase- 1 and acute kidney injury following cardiac surgery. Cardiorenal Med 4:12-21

40. Fang Y, Fu XJ, Gu C, Xu P, Wang Y, Yu WR et al (2011) Hydrogen-rich saline protects against acute lung injury induced by extensive burn in rat model. J Burn Care Res 32:e82-e91

41. Palipoch S (2013) A review of oxidative stress in acute kidney injury: protective role of medicinal plants-derived antioxidants. Afr J Tradit Complement Altern Med 10:88-93

42. Parihar A, Parihar MS, Milner S, Bhat S (2008) Oxidative stress and antioxidative mobilization in burn injury. Burns 34:6-17

43. Elks CM, Reed SD, Mariappan N, Shukitt-Hale B, Joseph JA, Ingram DK et al (2011) A blueberry-enriched diet attenuates nephropathy in a rat model of hypertension via reduction in oxidative stress. PLoS One 6:e24028

44. Shah S (2001) Role of iron in progressive renal disease. Am J Kidney Dis 37:S30-S33

45. Nishihashi T, Trandafir CC, Wang A, Ji X, Shimizu Y, Kurahashi K (2006) Hypersensitivity to hydroxyl radicals in rat basilar artery after subarachnoid hemorrhage. J Pharmacol Sci 100:234-236

46. Dagher PC, Mai EM, Hato T, Lee SY, Anderson MD, Karozos SC et al (2012) The p53 inhibitor pifithrin-alpha can stimulate fibrosis in a rat model of ischemic acute kidney injury. Am J Physiol Ren Physiol 302:F284-F291

47. Mariano F, Cantaluppi V, Stella M, Romanazzi GM, Assenzio B, Cairo M et al (2008) Circulating plasma factors induce tubular and glomerular alterations in septic burns patients. Crit Care 12:R42

48. Rana A, Sathyanarayana P, Lieberthal W (2001) Role of apoptosis of renal tubular cells in acute renal failure: therapeutic implications. Apoptosis 6:83-102

49. Yuan L, Wu MJ, Sun HY, Xiong J, Zhang Y, Liu CY et al (2011) VEGF-modified human embryonic mesenchymal stem cell implantation enhances protection against cisplatin-induced acute kidney injury. Am J Physiol Ren Physiol 300:F207-F218

50. Linkermann A, Chen G, Dong G, Kunzendorf U, Krautwald S, Dong Z (2014) Regulated cell death in AKI. J Am Soc Nephrol 25:2689-2701

51. Colpaert K, Hoste EA (2008) Acute kidney injury in burns: a story of volume and inflammation. Crit Care 12:192

52. Kinsey GR, Sharma R, Okusa MD (2013) Regulatory T cells in AKI. J Am Soc Nephrol 24:1720-1726

53. Proskuryakov SY, Konoplyannikov AG, Gabai VL (2003) Necrosis: a specific form of programmed cell death? Exp Cell Res 283:1-16

54. Ipaktchi K, Mattar A, Niederbichler AD, Hoesel LM, Vollmannshauser S, Hemmila MR et al (2006) Attenuating burn wound inflammatory signaling reduces systemic inflammation and acute lung injury. J Immunol 177:8065-8071

55. Hoesel LM, Mattar AF, Arbabi S, Niederbichler AD, Ipaktchi K, Su GL et al (2009) Local wound p38 MAPK inhibition attenuates burn-induced cardiac dysfunction. Surgery 146:775-785

56. Korkmaz A, Kolankaya D (2010) Protective effect of rutin on the ischemia/ reperfusion induced damage in rat kidney. J Surg Res 164:309-315

57. Dalboni MA, Quinto BM, Grabulosa CC, Narciso R, Monte JC, Durao M Jr et al (2013) Tumour necrosis factor-alpha plus interleukin-10 low producer phenotype predicts acute kidney injury and death in intensive care unit patients. Clin Exp Immunol 173:242-249

58. Chen HG, Xie KL, Han HZ, Wang WN, Liu DQ, Wang GL et al (2013) Heme oxygenase-1 mediates the anti-inflammatory effect of molecular hydrogen in LPS-stimulated RAW 264.7 macrophages. Int J Surg 11:1060-1066
59. Fujii Y, Shirai M, Inamori S, Shimouchi A, Sonobe T, Tsuchimochi H et al (2013) Insufflation of hydrogen gas restrains the inflammatory response of cardiopulmonary bypass in a rat model. Artif Organs 37:136-141

60. Chen XL, Sun L, Guo F, Wang F, Liu S, Liang X et al (2012) High-mobility group box-1 induces proinflammatory cytokines production of Kupffer cells through TLRs-dependent signaling pathway after burn injury. PLoS One $7:$ e50668

61. Liu CM, Ma JQ, Sun YZ (2012) Puerarin protects rat kidney from leadinduced apoptosis by modulating the PI3K/Akt/eNOS pathway. Toxicol Appl Pharmacol 258:330-342

62. Chen XL, Xia ZF, Yu YX, Wei D, Wang CR, Ben DF (2005) p38 mitogenactivated protein kinase inhibition attenuates burn-induced liver injury in rats. Burns 31:320-330

63. Ipaktchi K, Mattar A, Niederbichler AD, Hoesel LM, Hemmila MR, Su GL et al (2006) Topical p38MAPK inhibition reduces dermal inflammation and epithelial apoptosis in burn wounds. Shock 26:201-209

64. Kita T, Ogawa M, Sato H, Kasai K, Tanaka T, Tanaka N (2008) Role of p38 mitogen-activated protein kinase pathway on heart failure in the infant rat after burn injury. Int J Exp Pathol 89:55-63

65. Cao W, Xie YH, Li XQ, Zhang XK, Chen YT, Kang R et al (2011) Burninduced apoptosis of cardiomyocytes is survivin dependent and regulated by PI3 K/Akt, p38 MAPK and ERK pathways. Basic Res Cardio 106:1207-1220

66. Lv GF, Dong ML, Hu DH, Zhang WF, Wang YC, Tang CW (2011) Insulinmediated inhibition of p38 mitogen-activated protein kinase protects cardiomyocytes in severe burns. J Burn Care Res 32:591-599

67. Kita T, Yamaguchi H, Sato H, Kasai K, Tanaka T, Tanaka N (2004) Role of p38 mitogen-activated protein kinase pathway on renal failure in the infant rat after burn injury. Shock 21:535-542

68. Cassidy H, Radford R, Slyne J, O'Connell S, Slattery C, Ryan MP et al (2012) The role of MAPK in drug-induced kidney injury. J Signal Transduct 2012:463617

69. Malik S, Suchal K, Gamad N, Dinda AK, Arya DS, Bhatia J (2015) Telmisartan ameliorates cisplatin-induced nephrotoxicity by inhibiting MAPK mediated inflammation and apoptosis. Eur J Pharmacol 748:54-60

70. Tournier C, Hess P, Yang DD, Xu J, Turner TK, Nimnual A et al (2000) Requirement of JNK for stress-induced activation of the cytochrome c-mediated death pathway. Science 288:870-874

71. Marshall AH, Brooks NC, Hiyama Y, Qa'aty N, Al-Mousawi A, Finnerty CC et al (2013) Hepatic apoptosis postburn is mediated by c-Jun N-terminal kinase 2. Shock 39:183-188

72. Syrkina OL, Quinn DA, Jung W, Ouyang B, Hales CA (2007) Inhibition of JNK activation prolongs survival after smoke inhalation from fires. Am J Physiol Lung Cell Mol Physiol 292:L984-L991

73. Kyriakis JM, Banerjee P, Nikolakaki E, Dai T, Rubie EA, Ahmad MF et al (1994) The stress-activated protein kinase subfamily of c-Jun kinases. Nature 369:156-160

74. Seo JH, Lim JW, Kim H (2013) Differential role of ERK and p38 on NFkappa B activation in Helicobacter pylori-infected gastric epithelial cells. J Cancer Prev 18:346-350

75. Torres M, Forman HJ (2003) Redox signaling and the MAP kinase pathways. BioFactors 17:287-296

76. Itoh T, Fujita Y, Ito M, Masuda A, Ohno K, Ichihara M et al (2009) Molecular hydrogen suppresses FcepsilonRI-mediated signal transduction and prevents degranulation of mast cells. Biochem Biophys Res Commun 389:651-656

77. Qiu X, Li H, Tang H, Jin Y, Li W, YuSun et al (2011) Hydrogen inhalation ameliorates lipopolysaccharide-induced acute lung injury in mice. Int Immunopharmacol 11:2130-2137

78. Zang L, He H, Xu Q, Yu Y, Zheng N, Liu W et al (2013) Reactive oxygen species $\mathrm{H}_{2} \mathrm{O}_{2}$ and ${ }^{*} \mathrm{OH}$, but not $\mathrm{O}_{2}{ }^{*}(-)$ promote oridonin-induced phagocytosis of apoptotic cells by human histocytic lymphoma U937 cells. Int Immunopharmacol 15:414-423

79. Xu XF, Zhang J (2013) Saturated hydrogen saline attenuates endotoxininduced acute liver dysfunction in rats. Physiol Res 62:395-403

80. Sobue S, Yamai K, Ito M, Ohno K, Ito M, Iwamoto T et al (2015) Simultaneous oral and inhalational intake of molecular hydrogen additively suppresses signaling pathways in rodents. Mol Cell Biochem 403:231-241

81. Li ZY, Yang Y, Ming M, Liu B (2011) Mitochondrial ROS generation for regulation of autophagic pathways in cancer. Biochem Biophys Res Commun 414:5-8 
82. Kono H, Nakagawa K, Morita S, Shinoda K, Mizuno R, Kikuchi E et al (2013) Effect of a novel nuclear factor-kappaB activation inhibitor on renal ischemia-reperfusion injury. Transplantation 96:863-870

83. Lee JH, Jo YH, Kim K, Lee JH, Rim KP, Kwon WY et al (2013) Effect of $\mathrm{N}$-acetylcysteine (NAC) on acute lung injury and acute kidney injury in hemorrhagic shock. Resuscitation 84:121-127

84. Nozaki Y, Kinoshita K, Yano T, Asato K, Shiga T, Hino S et al (2012) Signaling through the interleukin-18 receptor alpha attenuates inflammation in cisplatin-induced acute kidney injury. Kidney Int 82:892-902

85. Rodrigues CE, Sanches TR, Volpini RA, Shimizu MH, Kuriki PS, Camara NO et al (2012) Effects of continuous erythropoietin receptor activator in sepsis-induced acute kidney injury and multi-organ dysfunction. PLoS One 7:e29893

86. Sleeman P, Patel NN, Lin H, Walkden GJ, Ray P, Welsh Gl et al (2013) High fat feeding promotes obesity and renal inflammation and protects against post cardiopulmonary bypass acute kidney injury in swine. Crit Care 17:R262
87. Zhang D, Li Y, Liu Y, Xiang X, Dong Z (2013) Paclitaxel ameliorates lipopolysaccharide-induced kidney injury by binding myeloid differentiation protein-2 to block Toll-like receptor 4-mediated nuclear factor-kappaB activation and cytokine production. J Pharmacol Exp Ther 345:69-75

88. Zhao H, Watts HR, Chong M, Huang H, Tralau-Stewart C, Maxwell PH et al (2013) Xenon treatment protects against cold ischemia associated delayed graft function and prolongs graft survival in rats. Am J Transpl 13:2006-2018

89. Song G, Tian H, Liu J, Zhang H, Sun X, Qin S (2011) $H_{2}$ inhibits TNF-alphainduced lectin-like oxidized LDL receptor-1 expression by inhibiting nuclear factor kappaB activation in endothelial cells. Biotechnol Lett 33:1715-1722

\section{Submit your next manuscript to BioMed Central and take full advantage of:}

- Convenient online submission

- Thorough peer review

- No space constraints or color figure charges

- Immediate publication on acceptance

- Inclusion in PubMed, CAS, Scopus and Google Scholar

- Research which is freely available for redistribution

Submit your manuscript at 